\title{
Behaviour and developmental effects of otitis media with effusion into the teens
}

\author{
K E Bennett, M P Haggard, P A Silva, I A Stewart
}

\begin{abstract}
Objective-To examine whether behavioural or cognitive sequelae of otitis media with effusion (OME) continue into late childhood and the early teens (11-18 years).

Setting-Data from a large multipurpose birth cohort study: the Dunedin multidisciplinary health and development study. Participants-Around 1000 children from the study. The main independent variable of interest was otological status of the child up to age 9.

Main outcome measures-Parent and teacher rated behaviour problems, including antisocial, neurotic, hyperactive, and inattentive behaviours, and tests of academic achievement including intelligence quotient (IQ), reading, and spelling were available in a high proportion of the cohort at ages 11 to 18 years.

Results-After adjustments for covariates such as socioeconomic status, hyperactive and inattentive behaviour problems were evident as late as 15 years, and lower IQ associated with OME remained significant to 13 years. The largest effects were observed for deficits in reading ability between 11 and 18 years.

Conclusions-No previous study considering behaviour problems as an outcome has followed children long enough to determine whether some of the early sequelae of OME are still present in the early to late teens. Some developmental sequelae of OME, particularly deficits in reading ability, can persist into late childhood and the early teens.

(Arch Dis Child 2001;85:91-95)
\end{abstract}

He Institute of University Park, Nottingham, UK

KE Bennett

M P Haggard

Dunedin

Multidisciplinary

Health and

Development Centre,

Dunedin, New Zealand

P A Silva

ENT department, University of Otago Medical School, Dunedin, New Zealand I A Stewart

Correspondence to:

Dr Kathleen Bennett, Trinity

Centre for Health Sciences,

St James's Hospital, Dublin

8 , Republic of Ireland

kbennett@stjames.ie

Accepted 19 February 2001

Keywords: otitis media; behaviour problems; academic achievement; longitudinal cohort study

Evidence of associations between otitis media with effusion (OME) during early childhood and later deficits in language, academic achievement, or behaviour is controversial. The number of studies finding such associations is almost equalled by those that do not, but low statistical power in most studies makes it unprofitable to seek a basis for their apparent “disagreements." Understandably, most studies of behavioural, language, and cognitive sequelae of OME have concentrated on short or medium term effects (up to the age of 7 years). ${ }^{12}$ Where sequelae have been found in the immediate aftermath of $\mathrm{OME}$ in midchildhood, estimates of their magnitude range from about one third to one half of a population standard deviation. For a common condition, this magnitude-although not large - merits study and explanation, for example by distinguishing the influences of persistent hearing loss from those of related respiratory and ear disease.

The duration of each long term effect of OME is the chief issue related to intervention policy. Therefore we examined associations between early OME and late developmental and behavioural sequelae in a national birth cohort. The cohort is based on a whole population; it is large enough to permit appropriate statistical control through adjustment for covariates. Cumulative history of OME through mid-childhood is important when considering late sequelae, since only those children with a longer duration of OME would be likely to have problems with behaviour and cognitive sequelae later in life. The repeated otological documentation and high follow up rates of the Dunedin cohort afford an opportunity to address this.

\section{Methods}

DUNEDIN MULTIDISCIPLINARY HEALTH AND DEVELOPMENT STUDY

A longitudinal investigation of health and development was undertaken on a sample of over 1000 children born in Dunedin, New Zealand, between 1 April 1972 and 31 March 1973, with assessments at birth and every second year from 3 to 15 , and then at 18,21 , and 26 years. ${ }^{4}$ The sample and methods have been extensively described elsewhere. ${ }^{34}$ Full otological data from the $11,13,15$, and 18 year assessments were available on $88 \%, 80 \%, 93 \%$, and $87 \%$ of original cases, respectively. General descriptive data, particularly on the early sequelae of otitis media with effusion, are presented elsewhere. ${ }^{4}$
INDEPENDENT VARIABLE-OTOLOGICAL ASSESSMENTS FROM AGE 5 TO 9 YEARS IN THE DUNEDIN STUDY

The otological status of the child, defined from age 5 to 9 years in the Dunedin study, provides an objective measurement of the cumulative history of OME (table 1), thus enabling us to exclude those with earlier but shorter term histories.

An otological examination was conducted on each child at $5,7,9,11,13$, and 15 years according to an assessment protocol, using otomicroscopy, impedance audiometry, and pure tone audiometry. ${ }^{4}$ As the disease generally resolves with growth, children with positive signs in this period will have had these previously. The converse is not true, so we believe it unlikely that we have missed significant cases. Ears were rated by otoscopy into 
Table 1 Children classified in the Dunedin sample according to severity of otological features from age 5 up to age 9

\begin{tabular}{|c|c|c|c|}
\hline Classification & Number & $\%$ & Description \\
\hline 1 & 53 & 5.5 & $\begin{array}{l}\text { Bilateral tubes on } \geqslant 1 \text { occasion, for OME with proven } \\
\text { hearing loss }\end{array}$ \\
\hline 2 & 45 & 4.7 & $\begin{array}{l}\text { Bilateral persistent OME with or without VT but no } \\
\text { evidence of HL exceeding } 25 \mathrm{~dB} \text { on at least one } \\
\text { occasion }\end{array}$ \\
\hline 3 & 26 & 2.7 & $\begin{array}{l}\text { Unilateral persistent OME with or without VT on at } \\
\text { least one occasion }\end{array}$ \\
\hline 4 & 118 & 12.3 & $\begin{array}{l}\text { Transient unilateral or bilateral OME on at least one } \\
\text { occasion }\end{array}$ \\
\hline 5 & 138 & 14.3 & No evidence of OME but scar tissue present \\
\hline 6 & 449 & 46.7 & $\begin{array}{l}\text { C tympanogram on at least one occasion but no OME } \\
\text { or type B tympanogram }\end{array}$ \\
\hline 7 & 133 & 13.8 & Always type A tympanogram in both ears \\
\hline Total & 962 & 100 & \\
\hline
\end{tabular}

HL, hearing loss; OME, otitis media with effusion; VT, ventilation tube.

five main categories: normal, fluid present, ventilation tubes present, acute otitis media, and other abnormalities.

Impedance audiometry (tympanometry) was performed on each ear, and classified according to Jerger. ${ }^{6}$ Hearing thresholds were obtained by pure tone audiometry for the complete sample at 500,1000, 2000, and 4000 $\mathrm{Hz}$. A mean hearing threshold was calculated across these frequencies for each ear at each phase. The information on hearing thresholds could be combined with that for the tympanogram and otoscopy to define middle ear status at each phase (table 1). Those meeting criteria for surgical treatment received ventilation (tympanostomy) tubes.

COVARIATES FOR STATISTICAL CONTROL

Covariates considered were sex, socioeconomic status, $^{7}$ and maternal malaise ${ }^{8}$ (for parent reported data only), derived from the Rutter malaise inventory ${ }^{9}$ at ages 11 to 15 , and sex and socioeconomic status only at age 18 . Analyses at earlier ages had suggested that socioeconomic status does not have an important influence on OME or its sequelae. ${ }^{4}$ The children in the Dunedin Study were slightly more advantaged in socioeconomic status than the New Zealand population as a whole, ${ }^{3}$ but included representatives of all socioeconomic groups. However, they were under-representative of Maori and Pacific Island children. While this will undersample the extremes of persistence of disease in the New Zealand population and reduce the power to detect associations, it avoids overestimating the strength of effect for prosperous societies.

DEPENDENT VARIABLES-BEHAVIOURAL AND DEVELOPMENTAL OUTCOMES IN THE DUNEDIN STUDY

Rutter parent and teacher behaviour scales were available at ages 11 and 13. At age 15 only data on parent and self reported behaviour problems were available, and at age 18 only self reported behaviour problems, using the more age appropriate revised behaviour problem checklist. ${ }^{10}$ Others, ${ }^{11}$ using this same cohort of children, have reported reliability coefficients between 0.82 and 0.84 . Subscales of antisocial, neurotic, hyperactive, and inattentive behaviour problems were derived by summing the relevant items from these behaviour questionnaires according to established derivations. ${ }^{9} 10$ Cognitive tests included verbal and non-verbal intelligence quotient (IQ) at 11 and 13 years (using the WISC scale ${ }^{12}$ ), the Dunedin spelling tests at 11 and 13 years, ${ }^{13}$ and the Burt reading test $^{14}$ at $11,13,15$, and 18 years. The Burt reading test was used up to age 18 , as cohort members were already familiar with the test and it has been shown to be a reliable and valid index of reading ability. ${ }^{14}$ More details on procedure and earlier results with these tests are given elsewhere. ${ }^{4}$

STATISTICAL ANALYSES

Regression analysis was used to examine the relation between the ear status and the outcome of interest, adjusting for socioeconomic group, sex, and - for the parent reported outcomes only-maternal malaise. This was performed at $11,13,15$, and 18 years. The $\beta$ coefficients in the tables provide a standardised metric for the relative strength of influences. A standardised partial $\beta$ coefficient of 0.1 or more indicates a moderate association.

The "ear status" variable documents the degree of persistence or transience of the condition, emphasising treatment and hearing loss. A high value indicates no ear or hearing problems. This variable is scaled as continuous to examine the association between degree of middle ear disease history and behavioural and developmental outcomes. All behaviour problem data are scored such that a higher value indicates worse behaviour problems, and all cognitive data in the direction of a higher score indicate better academic or cognitive attainment. Therefore we generally expect negative coefficients (with ear status) for behaviour outcomes, but positive coefficients for cognitive outcomes.

\section{Results}

OTOLOGICAL ASSESSMENTS FROM AGE 5 TO 9

YEARS

At age 5, 47.3\% of ears were normal (type A or no fluid present), $8.8 \%$ had evidence of fluid present (type B), and the remainder were intermediate (type $\mathrm{C} 1$ or $\mathrm{C} 2$ ). By age 7 there were $6.1 \%$ type B and 55\% type A tympanograms. By age 9 , there were $1.8 \%$ type $B$ and $62.3 \%$ type $\mathrm{A}$, and at age 11 the figures were $1.6 \%$ and $59.6 \%$, respectively.

Table 1 summarises the results of combining information on middle ear status on 962 children over the ages 5, 7, and 9 years, to summarise the OME history of each child over this period. The cumulative history reflects a combination of severity and duration so is likely to be more predictive of long term outcomes than analyses using single age predictors.

BEHAVIOUR AND DEVELOPMENTAL OUTCOMES FROM AGE 11 TO 18 YEARS

Table 2 gives the $\beta$ coefficients and $95 \%$ confidence intervals for the cumulative $\mathrm{OME}$ variable at age 9 influencing behaviour outcomes, after adjustment for social group, sex, 
Table 2 Standardised partial $\beta$ coefficients (95\% confidence intervals) for effects of ear status up to age 9 on reported behaviour problems

\begin{tabular}{|c|c|c|c|c|}
\hline & \multicolumn{4}{|l|}{ Age } \\
\hline & 11 years & 13 years & 15 years & 18 years \\
\hline \multicolumn{5}{|l|}{ Parent reported behaviour problem $\dagger$} \\
\hline Total behaviour problem score & $-0.079^{\star}(-0.154$ to -0.005$)$ & $-0.090^{\star \star}(-0.159$ to -0.021$)$ & $-0.100^{\star \star}(-0.165$ to -0.035$)$ & NA \\
\hline Antisocial/aggressive & $-0.015(-0.090$ to 0.060$)$ & $-0.06(-0.129$ to 0.009$)$ & $-0.072^{\star}(-0.137$ to -0.007$)$ & NA \\
\hline Neurotic & $-0.015(-0.090$ to 0.060$)$ & $-0.039(-0.108$ to 0.030$)$ & $-0.047(-0.112$ to 0.018$)$ & NA \\
\hline Hyperactive & $-0.084^{\star}(-0.159$ to -0.009$)$ & NA & NA & NA \\
\hline Inattentive & $-0.094^{\star \star}(-0.169$ to -0.020$)$ & $-0.095^{\star \star}(-0.164$ to -0.026$)$ & $-0.129^{\star \star \star}(-0.194$ to -0.064$)$ & \\
\hline \multicolumn{5}{|l|}{ Teacher reported behaviour problem $\ddagger$} \\
\hline Total behaviour problem score & $-0.041(-0.116$ to 0.034$)$ & NA & NA & NA \\
\hline Antisocial/aggressive & $-0.058(-0.133$ to 0.017$)$ & $-0.083^{\star}(-0.152$ to -0.014$)$ & NA & NA \\
\hline Neurotic & $0.015(-0.060$ to 0.090$)$ & $-0.090^{\star}(-0.159$ to -0.021$)$ & NA & NA \\
\hline Hyperactivity & $-0.071^{\star}(-0.146$ to 0.004$)$ & $-0.037(-0.106$ to 0.032$)$ & NA & NA \\
\hline Inattentive & $-0.054(-0.129$ to 0.021$)$ & $-0.110^{\star \star}(-0.179$ to -0.041$)$ & NA & NA \\
\hline
\end{tabular}

NA, data not available.

${ }^{\star} \mathrm{p}<0.05 ;{ }^{\star \star} \mathrm{p}<0.01 ;{ }^{\star \star \star} \mathrm{p}<0.001$.

†Adjusted for socioeconomic status, sex, and maternal malaise.

†Adjusted for socioeconomic status and sex.

Table 3 Standardised partial $\beta$ coefficients (95\% confidence intervals) for effects of ear status up to age 9 on developmental outcomes

\begin{tabular}{|c|c|c|c|c|}
\hline & \multicolumn{4}{|l|}{ Age } \\
\hline & 11 years & 13 years & 15 years & 18 years \\
\hline \multicolumn{5}{|l|}{ Teacher reported $\dagger$} \\
\hline Verbal IQ & $0.090^{\star \star}(0.0155$ to 0.016$)$ & $0.144^{\star \star \star}(0.073$ to 0.0215$)$ & NA & NA \\
\hline Non-verbal IQ & $0.062(-0.012$ to 0.136$)$ & $0.111^{\star \star}(0.040$ to 0.182$)$ & NA & NA \\
\hline Full IQ & $0.086^{\star}(0.012$ to 0.161$)$ & $0.144^{\star \star \star}(0.073$ to 0.215$)$ & NA & NA \\
\hline Reading & $0.099^{\star \star}(0.0245$ to 0.174$)$ & $0.116^{\star \star}(0.045$ to 0.187$)$ & $0.115^{\star \star}(0.050$ to 0.180$)$ & $0.112^{\star \star}(0.047$ to 0.177$)$ \\
\hline Spelling & $0.090 \star(0.016$ to 0.165$)$ & $0.115^{\star \star}(0.044$ to 0.186$)$ & NA & NA \\
\hline
\end{tabular}

NA, data not available

${ }^{\star} \mathrm{p}<0.05 ;{ }^{\star \star} \mathrm{p}<0.01 ;{ }^{\star \star \star} \mathrm{p}<0.001$.

†Adjusted for socioeconomic status and sex.

IQ, intelligence quotient.

and maternal malaise. The strongest associations with OME history up to age 9 lie in parent reported total behaviour problem score and inattentive behaviour at 13 and 15 years, and in teacher reported inattentive behaviour at 13 years.

Table 3 gives the standardised $\beta$ coefficients and $95 \%$ confidence intervals for the derived OME variable at age 9 influencing the developmental/cognitive outcomes, after adjustments for social group, sex, and maternal malaise. The strongest associations with $\mathrm{OME}$ history up to age 9 were with verbal IQ at 11 and 13 years, non-verbal and full IQ at 13 years, reading deficits at $11,13,15$, and 18 years, and spelling at 13 years. No speech and language data were available at these ages.

The Burt reading test was available at 11,13 , 15 , and 18 years, allowing a repeated measures analysis to be performed to examine patterns of association with age. Table 4 gives the mean

Table 4 Adjusted $\dagger$ means for Burt reading test at 11, 13, 15 , and 18 years in the Dunedin study

\begin{tabular}{lllll}
\hline \multirow{2}{*}{$\begin{array}{l}\text { OME status by age } \\
\text { 9 (see table 1) }\end{array}$} & \multicolumn{4}{l}{ Burt reading test } \\
\cline { 2 - 5 } & Age 11 & Age 13 & Age 15 & Age 18 \\
\hline 1 & 67.0 & 81.3 & 86.3 & 95.7 \\
2 & 72.3 & 81.0 & 86.8 & 94.3 \\
3 & 70.0 & 79.4 & 88.4 & 95.0 \\
4 & 69.6 & 80.7 & 87.6 & 94.3 \\
5 & 72.1 & 83.6 & 91.0 & 97.3 \\
6 & 72.3 & 84.5 & 90.8 & 97.6 \\
7 & 75.4 & 87.1 & 92.7 & 99.2 \\
Maximum & 8.4 & 7.6 & 6.4 & 4.4 \\
$\quad$ difference & & & & \\
Overall means & 72.4 & 84.1 & 90.4 & 97.1 \\
Standard error & 2.6 & 2.2 & 1.9 & 1.4 \\
\hline
\end{tabular}

†Adjusted for socioeconomic group and sex. OME, otitis media with effusion. scores by ear status across age in years. For this purpose, the ear status at age 9 was collapsed to a three category stratification, by grouping categories 1 and 2, 3 and 4, and 5-7 as given in table 1, to represent sustained bilateral, unilateral/transient, and no evidence of OME. After adjustment for socioeconomic group and sex, the otological status of the child by age 9 had a marginal effect on the mean reading score over all ages $(p=0.054$, test for linear trend over time).

\section{Discussion}

Many previous studies considering long term sequelae have methodological problems, including a high rate of attrition and inadequate control for probable confounding variables. Only a few studies ${ }^{15-18}$ have considered effects of otitis media after the age of 9 . Their results are inconclusive as to whether behavioural or developmental sequelae continue into the teenage years. However, most of these studies had sample sizes that were too small to detect the modest effect that could reasonably be expected, given the remitting nature of the disease, or else they used highly selected populations. One study ${ }^{16}$ showed that 12 children with multiple episodes of otitis media in the first year of life performed less well in a variety of communication tasks, including language and speech at age 9, than a group of children who were effusion-free in their first year. Secord et $a l$, in a group of 84 learning disabled children and adolescents, showed that early onset OME can lead to serious cognitive deficits at age 9, particularly in auditory-verbal abilities involving sequential processing. ${ }^{17}$ Roberts et al found 
no association between $\mathrm{OME}$ in the first 3 years of life and cognitive, academic and behaviour problems at 12 years of age in a group of socially disadvantaged children. ${ }^{18}$

Unrealistically large effects (in view of the modest magnitude of those in younger children) would have to be postulated to give such small studies a good chance of finding an effect. The magnitude of an effect found in a study will depend upon the extremity of definition of the index group - that is, case severity; this in turn influences the required sample size and cost of a population study, especially when studying unusual degrees of disease severity or persistence. To show a simple group difference of modest magnitude (0.33 SD) at $\mathrm{p}=0.05$ (two tailed test) at $90 \%$ power between two equally sized groups of cases and controls requires around 200 children per group. With such a powerful design, observational studies on population cohorts give somewhat disappointing power relative to the apparently large sample size. In a population (rather than case-control) study, numbers of the order of 1000 are the minimum for showing effects on a condition having a nominal prevalence of $10 \%$; this is partly because of the few extreme cases in an unselected population.

Overall the results suggest that correlates of an early OME history, or the sequelae of early OME history, can still exert some influence well into late childhood but not beyond. Against this background, the deficits in reading ability shown here constitute a substantially new finding.

\section{BEHAVIOUR PROBLEM OUTCOMES}

The strongest finding was OME history associated with parent reported inattentive behaviour at 11,13 , and 15 years, but also some residual antisocial behaviour at 15 years. This would not necessarily have been expected at such a late age. Some associations were also found for teacher reported behaviour problems and OME history, in particular antisocial, neurotic, and inattentive behaviour at age 13 but hardly any at age 11 . Behaviour problems may result from illness related morbidity or absence from school, but this explanation is unlikely as the tympanogram prevalences show that by 9 years of age most children are free from the disease.

In the 1970 British birth cohort study ${ }^{19}$ significant associations were found between parent reported hearing difficulty up to 5 years and parent reported behaviour problems (derived from the Rutter A scale ${ }^{9}$ ) at 10 years (including antisocial, neurotic, and hyperactive behaviour). ${ }^{20}$ Significant associations between parent reported hearing difficulty up to 5 years and teacher reported behaviour problems (derived from the 52 item scale combining items from the Rutter B scale and the Connors teacher rating scale $^{9}$ ) at 10 years (antisocial and neurotic behaviour problems) ${ }^{20}$ and 16 years (antisocial, neurotic, inattentive, hyperactive, and clumsy behaviour problems; unpublished data) were also reported. The strongest of these associations at 16 years in the 1970 British birth cohort study appeared to be with hyperactive and inattentive behaviour. This was also found at 15 years in the Dunedin cohort, where parent reported inattentive behaviour was associated with cumulative ear history by age 9 .

Thus antisocial, neurotic, and some inattentive behaviours in late childhood (10-13 years) seem to be associated with middle ear disease, and there is still a residual disposition to inattentive/hyperactive behaviour at 15-16 years.

DEVELOPMENTAL AND COGNITIVE OUTCOMES At age 13, reading and spelling appeared to be influenced by OME. More restricted data on developmental sequelae were available in the late teens (15-18 years). Reading at 15 and 18 years was significantly associated with ear status at age 9 . The Burt reading test has a ceiling at a score of 110 , so by the latter ages there is little room for improvement. This might be expected to reduce the sensitivity of the test in detecting small differences between groups; however, it has been shown to discriminate well even up to age 18. The expected compression of the variance, and hence of the group differences, is a reason why we believe this result is genuine.

There appeared to be at least a two year delay in mean reading scores for those in categories 1 and 2 (persistent bilateral B tympanograms) compared with category 7 (normal ears throughout) in the Dunedin cohort. Given the multiple determinants of reading, the causal pathway from early OME to reading effects is unclear. In a review of studies on reading and OME, Lous ${ }^{21}$ concluded that children with early OME had "caught up" in reading by school age, and that the observed low correlation of reading deficit with OME was not of practical importance. Detailed interpretation should therefore be suspended pending replication, given the multiplicity of factors influencing reading and the inconsistent effects on reading in late childhood.

Nevertheless, the findings of various studies examining the effects of OME on children's reading at various ages gives grounds for believing that effects can be shown under some circumstances. In a large study, Luotonen et al found that those children with more than four OME episodes before age 3 were rated by teachers as performing less well on reading comprehension by age 9 than those having fewer episodes. ${ }^{22}$ Updike $^{23}$ found a significant effect of OME on reading at 6-7 years and correlations between auditory perception skills and word recognition and reading comprehension. In the 1970 British birth cohort study we found $^{20}$ an association $(p<0.05)$ between the Edinburgh reading test ${ }^{24}$ at 10 years and parent reported history of ear discharge up to age 5 years ${ }^{25}$; reading data were not available for the 16 year cohort. One possible explanation for the inconsistency between Lous's overall conclusion and certain positive results lies in the variety of case definitions, and the use of tests with differing loadings. As a skill, reading has visual, linguistic, cognitive, motivational, and cultural components. A possible mechanism is less efficient phonological coding in short term memory, which is a predictor of early reading ability. In a well controlled study we have 
shown ${ }^{25}$ that phonological coding is influenced in 5-7 year olds by otitis media. However, we do not suggest this is the main causal route to the long term reading effect. The long term effect is not necessarily a mystery; it may reflect an underlying influence that reasserts itself as reading becomes more an aspect of identity and motivation than of formal education.

At ages 11 and 13 years, the effect of OME history on IQ was statistically significant here, being more evident for the verbal IQ scale as expected. Few other studies have examined the relation between IQ and middle ear disease as late as this. At 7 years, Teele et al found an association between middle ear disease and lower IQ, both verbal and performance. ${ }^{1}$ At 10 years we found no significant effect for $I Q,{ }^{20}$ measured using the British Ability Scale ${ }^{26}$ (BAS, similar to the American Differential Ability Scales) in the 1970 British birth cohort study.

In a review of speech and language sequelae from $\mathrm{OME},{ }^{2}$ the evidence on very early speech and language has been found to be quite strong. No data are available in the Dunedin cohort on speech and language. However, in the 1970 British birth cohort study, speech articulation (questionnaire based) and language (English picture vocabulary test) as reported by the teacher at 10 years in the 1970 British birth cohort study were both influenced $(p<0.01)$ by a history of early middle ear disease. ${ }^{20}$ Many language studies fail to find effects after 5 years, and as few data have been published on language sequelae after age 8 no conclusions can be drawn about whether the reading effects should be attributed to a more general linguistic factor.

The relations found between middle ear disease, behaviour problems, and deficits in cognition may be the joint effects of a common cause rather than any one causing the other. However, the "dose-response" patterns of deficits in reading ability in table 4 suggest that the effects are disease related. In summary, we believe there are some continuing effects of OME history on academic achievement and reading in the teenage years, but these are diminishing by the age of 18 .

\section{CONCLUSIONS}

The results from the analyses of a national birth cohort provide new findings on longer term sequelae of OME. In particular, early middle ear disease history appears to have a deleterious effect on reading ability, verbal IQ, and behaviour problems, as reported by parents and teachers, including inattentive and hyperactive behaviour. Because of the links to academic performance and social behaviour in the subset of children persistently affected by $\mathrm{OME}$, the future challenge for health professionals and parents will be to identify persistent, long term cases of OME and to intervene in ways that evidence shows to be justified.
This research would not have been possible without the contribution of the Health Research Council of New Zealand and the study members and their parents who have supported the study over the past 26 years. We also acknowledge Sheila Williams for help with supplying the Dunedin cohort data. Research support from Defeating Deafness (Hearing Research Trust, UK) and Deafness Research Foundation, New Zealand. Most of this work was carried out while the first author was an MRC training fellow in health services research at the MRC Institute of Hearing Research, Nottingham, UK.

1 Teele DW, Klein JO, Chase C, et al, and the Greater Boston Otitis Media Study Group. Otitis media in infancy and intellectual ability, school achievement, speech and language at age 7 years. F Infect Dis 1990;162:685-94.

2 Friel-Patti S. Otitis media with effusion and the development of language: a review of the evidence. Top Language Disord 1990;11:11-22.

3 Silva PA, Stanton W. From child to adult; the Dunedin multidisciplinary health and development study. Auckland: Oxford University Press, 1996.

4 Chalmers D, Stewart I, Silva P, et al. Otitis media with effusion in children - the Dunedin study. Oxford: Blackwell, 1989.

5 Silva P, Kirkland C, Simpson A, et al. Some developmental and behavioural problems associated with bilateral otitis media with effusion. F Learn Disabil 1982;15:417-21.

6 Jerger J. Clinical experience with impedance audiometry. Arch Otolaryngol 1970;92:311-24.

7 Elley WB, Irving JC. A socio-economic index for New Zealand based on levels of education and income form the 1966 census. F Educ Stud 1972;7:153-67.

8 Rutter M. Commentary: some focus and process considerations regarding effects of parental depression on children. Dev Psych 1990;26:60-67.

9 Rutter M, Tizard J, Whitmore K. Education, health and behaviour. London: Longman, 1970.

10 Quay HC, Peterson DR. Manual for revised behaviour problem checklist. University of Miama, Florida: Coral Gables, 1987.

11 Pisecco S, Baker DB, Silva PA, et al. Behavioural distinctions in children with reading disabilities and/or ADHD. F Am Acad Child Adolesc Psychiatry 1996;35:147784

12 Weschler D. The Weschler intelligence scale for childrenrevised. New York: Psychological Corporation, 1974.

13 Silva PA, Smith CTW, Pearce DW. The Dunedin spelling tests. Dunedin: Dunedin Multidisciplinary Health and Development Research Unit, Department of Pediatics and Child Health, University of Otago Medical School, 1984.

14 New Zealand Council for Educational Research. The Burt word reading test. New Zealand revision. Wellington: Lithoprint, 1981.

15 Roberts JE, Schuele CM. Otitis media and later academic performance. The linkage and applications for intervention. Top Language Disord 1990;11:43-62.

16 Ruben RJ, Wallace IF, Gravel J. Long term communication deficiencies in children with otitis media during their first year of life. Acta Otolaryngol 1997;117:206-7.

17 Secord GJ, Erickson MT, Bush JP. Neuropsychological sequelae of otitis media in children and adolescents with learning difficulties. F Pediatr Psychol 1988;13:531-42.

18 Roberts JE, Burchinal MR, Clarke-Klein SM. Otitis media in early childhood and cognitive, academic and behaviour outcome at 12 years. F Pediatr Psychol 1995;20:645-60.

19 Butler NR, Golding J. From birth to five. Oxford: Pergamon Press, 1986.

20 Bennett KE, Haggard MP. Behaviour and cognitive outcomes from middle ear disease. Arch Dis Child 1999;80: $28-35$.

21 Lous J. Otitis media and reading achievement: a review. Int f Pediatr Otorhinolaryngol 1995;32:105-21.

22 Luotonen M, Uhari M, Aitola L, et al. Recurrent otitis media during infancy and linguistic skills at the age of 9 years. Pediatr Infect Dis 7 1996;15:854-8.

23 Updike C. Reading skills and auditory processing ability in children with chronic otitis media in early childhood. Ann Otol Rhinol Laryngol 1992;191:530-7.

24 Edinburgh reading test. Godfrey Thompson Unit, Edinburgh University. Kent: Hodder and Stoughton, 1978.

25 Hind SE, Wade AR, Haggard MP. Optimization of a cognitive test battery for assessing OME sequelae. In: Lim D, Bluestone C, eds. Proceedings of the Sixth International Symposium of Recent Advances in Otitis Media, 4-8 June 1995, Fort Lauderdale, Florida. New York: Marcel Decker, 1996 346-50.

26 Elliot CD, Murray DJ, Pearson LS .British ability scales. NFER, 1978 